\title{
Pengaruh Curing Time Terhadap Sifat Mekanis Komposit Epoxy/Carbon Fiber dan Epoxy/Glass Fiber dengan Metode Manufaktur Bladder Compression Moulding
}

\author{
M. I. Putra* dan G. Nugroho \\ Departemen Teknik Mesin dan Industri, Fakultas Teknik, Universitas Gadjah Mada. \\ Jl. Grafika No.2, Kompleks UGM, Yogyakarta 55281, Indonesia, \\ Telp. (0274) 521673 \\ e-mail: bungidris010@gmail.com
}

\begin{abstract}
Abstrak
Material komposit banyak diminati karena memiliki keunggulan yang dibutuhkan dalam bidang engineering. Metode manufaktur komposit secara umum terbagi dua yaitu metode cetakan terbuka (open mould) dan metode cetakan tertutup (close mould). Bladder compression moulding merupakan metode manufaktur komposit cetakan tertutup yang mengaplikasikan tekanan dan pemanasan dalam kerjanya. Tujuan penelitian ini untuk memperoleh waktu optimum pada manufaktur komposit dengan metode bladder compression moulding serta mempelajari pengaruh variasi curing time terhadap sifat mekanis produk komposit yang dihasilkan. Penelitian ini menggunakan dua jenis material serat yaitu serat karbon dan serat gelas. Sebanyak 6 lapis Serat karbon dan 6 lapis serat gelas dibentuk dalam sebuah cetakan (mould) dengan resin epoksi sebagai matriksnya pada tekanan $7 \mathrm{Bar}$ dan temperatur $120^{\circ} \mathrm{C}$ dengan variasi curing time 10 menit sampai dengan 70 menit dengan kenaikan tiap 10 menit. Hasil uji tarik menunjukkan bahwa kekuatan tertinggi komposit epoksi/serat karbon yaitu pada curing time 40 menit (351MPa) dan komposit epoksi/serat gelas diperoleh pada curing time 30 menit $(279 \mathrm{MPa})$. Kesimpulan penelitian yaitu produktifitas komposit dapat dimaksimalkan dengan diperolehnya waktu optimum pada pembentukan komposit dengan metode bladder compression moulding.
\end{abstract}

Kata kunci : Bladder compression moulding, sifat mekanis, epoksi/serat karbon, epoksi/serat gelas.

\begin{abstract}
Composoite material has many advantages was needed in engineering. Generally, composite manufacturing are divided in two methods, openmould and close mouldsystems. Bladder compression moulding is a method of close mould composite manufacturing involves pressure and heating system in the process. The purpose of this study is to obtain the optimum time in composite manufacturing using bladder compression molding method and to study the effect of curing time variations on the mechanical properties of composite products produced at $7 \mathrm{KPa}$ and $120^{\circ} \mathrm{C}$. This study uses two types of fiber, namely carbon fiber and glass fiber. Total of 6 layers carbon fiber and 6 layers glass fiber were formed in a mold which epoxy resin is the matrix with variations of holding time at 10 to 70 minutes with curing variations every 10 minutes. Tensile test results showed that the highest strength of carbon fiber / epoxy composites was at a curing time of 40 minutes (351MPa) and glass fiber/ epoxy obtained at a curing time of 30 minutes (279 MPa). The conclusion of this study was that the productivity of composite manufacturing can be maximized with optimum time for composite forming by bladder compression moulding method.
\end{abstract}

Keywords : Bladder compression moulding, mechanical properties, carbon fiber/epoxy, glass fiber/ epoxy. 


\section{PENDAHULUAN}

Komposit merupakan material yang tersusun dari dua material atau lebih yang secara spesifik memiliki sifat mekanik yang berbeda dan tidak saling melarutkan sehingga saat digabungkan masih dapat dibedakan secara makroskopik dan akan membentuk material yang mewakili material penyusunnya. Karakteristik setiap bahan penyusun akan mempengaruhi karakter komposit yang dibentuk. Perkembangan ruang lingkup komposit saat ini merangkum hampir semua bahan engineering termasuk plastik, logam, keramik, kopolimer dan lain-lain (Jones, 1999).

Komposit memiliki beberapa keunggulan diantaranya ringan, kuat dan tahan korosi. Komposit banyak diminati karena sifatnya yang mampu menjawab kebutuhan masyarakat modern yaitu kuat namun tetap ringan. Pesatnya perkembangan dalam bidang material dan manufaktur menjadikan komposit mampu digunakan dalam beragam aplikasi seperti struktur pesawat terbang dan otomotif yang memerlukan bahan-bahan ringan namun tetap kuat (Mallick, 2007).

Metode pembentukan komposit yang umum ditemui diantaranya adalah hand lay up, spray lay up, vacuum baging, Resin transfer moulding dan lain-lain. Jenis perlakuan dalam proses pembentukan komposit pada umumnya melibatkan pemanasan dan penekanan. Bladder compression moulding merupakan metode pembentukan komposit yang masih tergolong baru namun efektif dalam pembentukan komposit karena dapat membuat produk berongga dan kontur tertutup lainnya. Kualitas produk komposit yang dibentuk dengan bladder compression moulding sangat dipengaruhi oleh tiga variabel yaitu besarnya tekanan (pressure), suhu (temperature), dan waktu (time) (Anderson \& Altan, 2012).

Ismadi (2018) meneliti pengaruh tekanan pada pembentukan komposit epoksi/serat karbon menggunakan metode bladder compression moulding dengan curing time selama 12 jam. Hasil penelitian menunjukkan bahwa tekanan optimum yang dapat dijadikan referensi dalam proses pembentukan komposit dengan metode bladder compression molding adalah 7 Bar. Penelitian lain menjelaskan bahwa temperatur optimum pada pembentukan komposit dengan metode bladder compression molding adalah $120^{\circ} \mathrm{C}$ dengan curing time selama 60 menit (Setyoko, 2018). Komposit epoksi/serat karbon maupun komposit epoksi/serat gelas yang dihasilkan menggunakan sistem pemanas rata-rata memiliki kinerja mekanis yang lebih tinggi dibandingkan komposit yang dibentuk pada room temperature (Singh dkk, 2018).

Curing time merupakan salah satu parameter penting yang perlu diperhatikan dalam proses manufaktur komposit karena curing yang tidak sempurna atau terlalu cepat dapat mengakibatkan berkurangnya ketahanan termal, transisi temperatur, ketahanan lembab, ketahanan fatik, kekuatan matriks, sifat-sifat kekakuan dan curing time yang terlalu lama tidak menguntungkan dalam sebuah proses manufaktur (Mazumdar, 2002).

Belum ada informasi spesifik tentang curing time optimum yang dapat dijadikan acuan pada pembentukan komposit dengan metode bladder compression moulding. Oleh karena itu, penelitian ini bertujuan untuk memperoleh waktu optimum pada pembentukan komposit dengan metode bladder compression moulding menggunakan sistem pemanas internal serta mengetahui pengaruh variasi curing time terhadap sifat mekanis khususnya kekuatan tarik dari produk komposit yang dihasilkan dengan metode bladder compression moulding.

\section{METODE PENELITIAN}

Bladder compression moulding merupakan proses pembentukan komposit dengan menggunakan bladder di dalam cetakan tertutup. Cetakan berfungsi memberi bentuk akhir pada bagian luar produk dan umumnya terbuat dari bahan logam. Sedangkan bladder berfungsi meneruskan 
tekanan yang diterima dari kompressor ke sisi dalam untuk memadatkan bahan komposit selama proses curing. Bladder dibuat menyerupai bentuk produk komposit. Pembuatan bladder dapat dilakukan dengan memanfaatkan cetakan menggunakan female mould. Bladder dapat terbuat dari bahan lateks atau silicon rubber. Berbeda dengan bladder moulding konvensional yang mana proses curing sering dipanaskan menggunakan sumber panas eksternal seperti oven, bladder compression moulding menggunakan sistem pemanasan internal dalam mould. Selain itu, kelebihan metode ini yaitu mampu menahan tekanan tinggi sehingga menghasilkan komposit yang kuat dengan fraksi serat tinggi (Anderson \& Altan, 2014). Penggunaan sistem pemanas internal pada metode bladder compression moulding memiliki nilai efektifitas yang lebih baik dalam hal konsumsi energi dibandingkan sistem pemanasan eksternal (Budi, 2020).

Jenis serat yang digunakan pada penelitian ini adalah serat karbon woven roving (WR 240) dan serat gelas woven roving (WR 200) sebagai penguat serta resin epoksi tipe Bisphenol A-Epichlorobydrin dengan hardener jenis epoxy hardener EPH 555 tipe Cycloalipathic Anine sebagai matriks dengan perbandingan resin dan hardener yang digunakan yaitu 1: 1. Serat penguat komposit ditunjukkan pada Gambar 1.

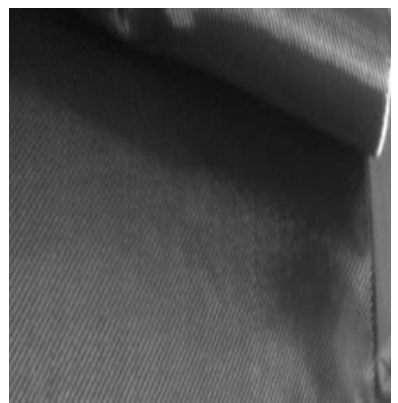

(a)

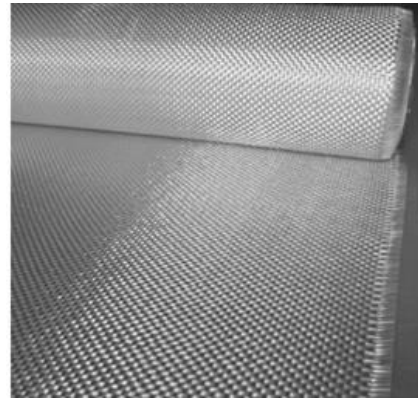

(b)

Gambar 1. (a). Serat karbon (b). Serat gelas

Manufaktur komposit dilakukan dengan metode bladder compression moulding menggunakan sistem pemanasan dan penekanan dalam proses kerjanya. Cetakan komposit yang digunakan pada penelitian ini terbuat dari bahan Alumunium seri 6 yang tardiri dari dua bagian dengan dimensi total saat tertutup $322 \mathrm{~mm}$ x $240 \mathrm{~mm}$ x $80 \mathrm{~mm}$. Pada setiap mould juga dibuat ruang untuk pemanas dan thermocontrol system sebagai pengatur temperatur. Jenis bladder yang digunakan adalah sintetic rubber dengan ekspansi total 30\%. Mould dan bladder yang digunkan dalam penelitian ini ditunjukkan pada Gambar 2.

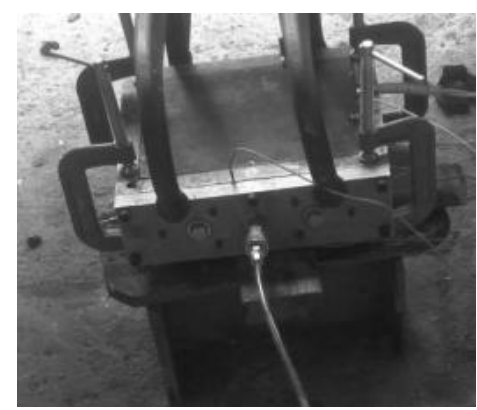

(a)

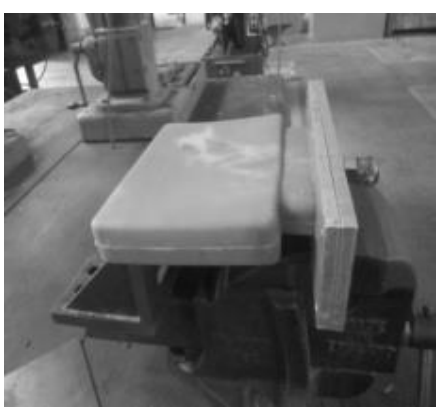

(b) 
Gambar 2. (a). Cetakan (b). Bladder

Produk komposit pada penelitian ini dihasilkan dari masing-masing 6 lapis serat karbon dan 6 lapis serat gelas pada takanan $7 \mathrm{Bar}$ dan temperatur $120^{\circ} \mathrm{C}$ dengan curing time 10 menit hingga 70 menit dengan variasi curing time tiap 10 menit. Seluruh alat dan bahan yang digunakan dalam percobaan ini dirangkai dalam suatu eksperimental setup seperti ditunjukkan pada Gambar 3.

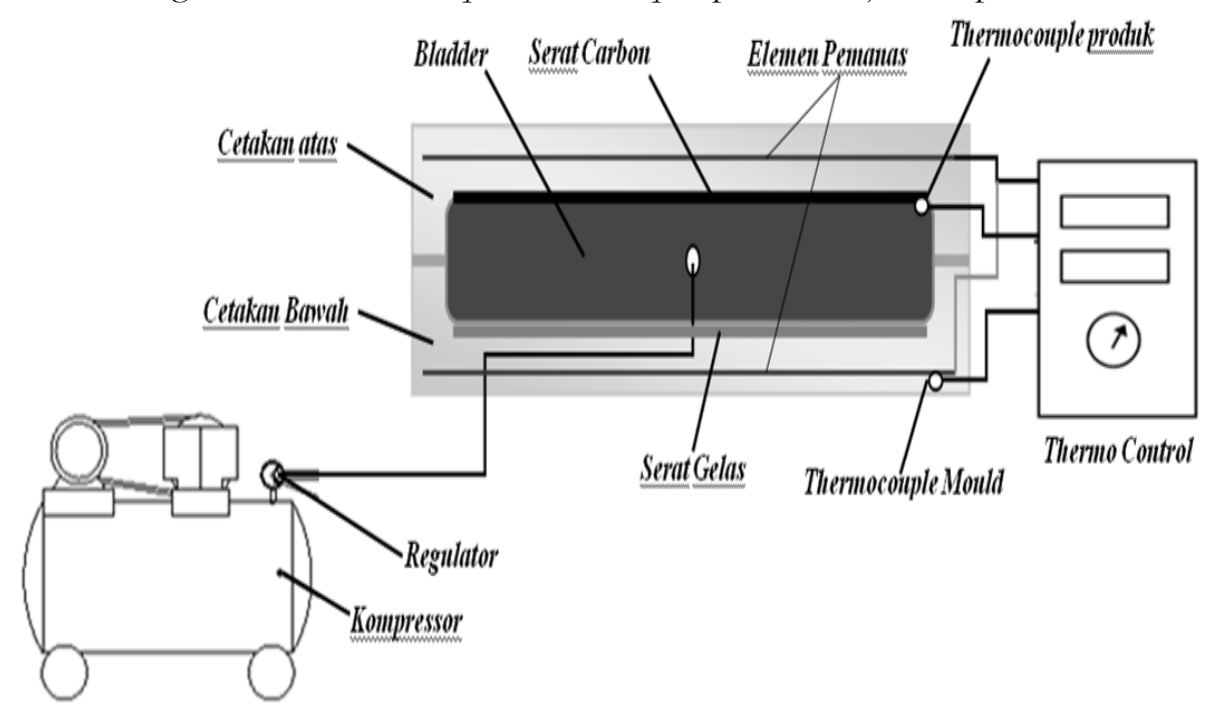

Gambar 3. Experimental Set up

Proses pembuatan produk komposit dengan metode bladder compression moulding dilakukan dengan langkah-langkah sebagai berikut:

Pertama, Permukaan cavity dibasahi dengan release gel, kemudian dioleskan resin epoksi yang telah dicampurkan dengan hardener pada masing-masing cavity mould. Satu lapis serat karbon woven diletakkan pada salah satu cavity (mould atas) dan satu lapis serat gelas pada bagian cavity yang lain (mould bawah). lalu oleskan kembali resin epoksi di atas lembaran serat karbon dan serat gelas. Proses diulangi hingga lapisan serat karbon dan lapisan serat gelas berjumlah masing-masing 6 lapis.

Kedua, bladder diletakkan di atas bahan komposit pada cetakan bawah dan bagian mould yang lain di cetakan atas lalu mould ditutup. tekanan bladder dinaikkan hingga 7 Bar lalu mould dipanaskan hingga mencapai temperatur $120^{\circ} \mathrm{C}$. Pada tekanan dan temperatur ini $\left(7 \mathrm{Bar}, 120^{\circ} \mathrm{C}\right)$ ditahan selama 10 menit. Setelah itu pemanasan dihentikan dan mould didinginkan serta tekanan bladder diturunkan dan produk komposit dapat dilepas dari mould. Langkah sebelumnya juga dilakukan untuk variasi curing time yang lain pada 20 menit hingga 70 menit.

Produk komposit yang dihasilkan kemudian dipotong dalam bentuk spesimen uji tarik untuk mengetahui kekuatan tarik material. Standar uji tarik yang digunakan yaitu ASTM D-638 type III dengan dimensi panjang total $165 \mathrm{~mm}$ dan lebar $19 \mathrm{~mm}$. Spesimen uji tarik komposit ditunjukkan pada Gambar 4. 


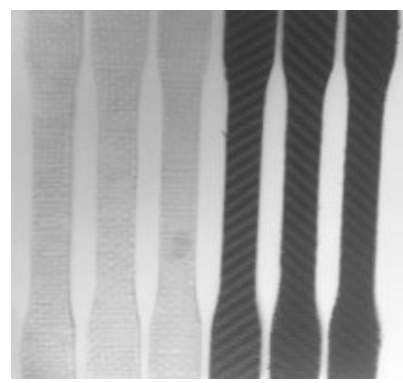

Gambar 4. Spesimen uji tarik ASTM D-638

\section{HASIL DAN PEMBAHASAN}

Kekuatan tarik komposit yang dihasilkan diuji dengan mengikuti standard ASTM D-638 (ASM Handbook, 2000). Pengujian tarik menggunakan universal testing machine (UTM) merk Zwick/Roll dengan kapasitas $20 \mathrm{KN}$ seperti pada Gambar 5.

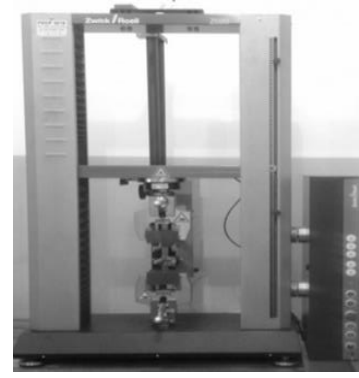

Gambar 5. Universal Testing Machine (UTM) merk Zwick/Roll

Hasil pengujian tarik material komposit epoksi/serat karbon dan komposit epoksi/serat gelas diperoleh hasil berupa gaya yang dibutuhkan, kekuatan tarik dan modulus tarik seperti pada tabel 1.

Tabel 1. Data Hasil Pengujian Tarik Komposit

\begin{tabular}{llclllll}
\hline \multicolumn{7}{c}{ Komposit Epoksi/Serat Karbon } \\
\hline \multirow{2}{*}{ No } & $\begin{array}{c}\text { Time } \\
{[\mathrm{min}]}\end{array}$ & $\begin{array}{c}\text { Force } \\
{[\mathrm{N}]}\end{array}$ & $\begin{array}{c}\sigma \mathrm{M} \\
{[\mathrm{MPa}]}\end{array}$ & $\begin{array}{c}\text { Et } \\
{[\mathrm{MPa}]}\end{array}$ & $\begin{array}{c}\mathrm{h} \\
{[\mathrm{mm}]}\end{array}$ & $\begin{array}{c}\mathrm{b} \\
{[\mathrm{mm}]}\end{array}$ & $\begin{array}{c}\mathrm{A} 0 \\
{\left[\mathrm{~mm}^{2}\right]}\end{array}$ \\
\hline 1 & 10 & 3976,95 & 214 & 4000 & 1.3 & 14.17 & 18.89 \\
2 & 20 & 5447,90 & 268 & 5680 & 1.4 & 13.4 & 20.33 \\
3 & 30 & 5453,44 & 316 & 6920 & 1.31 & 13.13 & 17.29 \\
4 & 40 & 5975,92 & 351 & 6860 & 1.26 & 13.4 & 17.02 \\
5 & 50 & 6098,33 & 308 & 4860 & 1.3 & 13.5 & 18.11 \\
6 & 60 & 5753,33 & 303 & 7400 & 1.3 & 13.5 & 19.02 \\
7 & 70 & 5904,15 & 315 & 6390 & 1,3 & 13,7 & 20,1 \\
\hline \multicolumn{7}{c}{ Komposit Epoksi/Serat Gelas } \\
\hline No & Time & Force & $\sigma \mathrm{M}$ & Et & $\mathrm{h}$ & $\mathrm{b}$ & $\mathrm{A} 0$
\end{tabular}


M. I. Putra dan G. Nugroho / Journal of Mechanical Design and Testing 3(1), (2021), 20-28

\begin{tabular}{llllllll} 
& {$[\mathrm{min}]$} & {$[\mathrm{N}]$} & {$[\mathrm{MPa}]$} & {$[\mathrm{MPa}]$} & {$[\mathrm{mm}]$} & {$[\mathrm{mm}]$} & {$\left[\mathrm{mm}^{2}\right]$} \\
\hline 1 & 10 & 2960,14 & 213 & 3690 & 1,2 & 13,61 & 13.88 \\
2 & 20 & 3472,21 & 245 & 4180 & 1,04 & 13,56 & 14.19 \\
3 & 30 & 3769,39 & 279 & 4360 & 1,0 & 13,66 & 13.53 \\
4 & 40 & 3834,04 & 273 & 4530 & 1,02 & 13,75 & 14.03 \\
5 & 50 & 3786,77 & 267 & 4442 & 1,02 & 13,85 & 14.22 \\
6 & 60 & 3872,80 & 262 & 4613 & 1,04 & 13,83 & 14.25 \\
7 & 70 & 3758,18 & 266 & 4400 & 1,04 & 13,95 & 14,81 \\
\hline
\end{tabular}

Hasil pengujian tarik menunjukkan kekuatan komposit epoksi/serat karbon meningkat dari curing time 10 menit (214 MPa) hingga mencapai nilai kekuatan tarik tertinggi pada 40 menit (351 $\mathrm{MPa}$ ) dengan modulus tarik $6860 \mathrm{MPa}$. Meningkatnya nilai kekuatan tarik karena dipengaruhi oleh perilaku ikatan antar muka resin dan serat pada setiap variasi curing time yang semakin meningkat. Pemanasan pada temperatur proses $120^{\circ} \mathrm{C}$ memudahkan mobilisasi resin dalam laminasi serat dan menjadikan semakin banyak ikatan silang (crosslinking) yang terjadi. Semakin banyak ikatan silang (crosslinking) maka kekuatan tarik komposit akan semakin meningkat (Singh $\mathrm{dkk}$, 2018). Kemudian pada curing time berikutnya kekuatan tarik cenderung konstan (308 $\mathrm{MPa}$ ) pada waktu tahan 50 menit dan 60 menit (303 MPa) dengan modulus tarik $7400 \mathrm{MPa}$. Pengujian tarik pada komposit epoksi/serat gelas juga menunjukkan peningkatan kekuatan tarik dari curing time 10 menit (213 MPa) dan 20 menit (245 MPa) hingga mencapai kekuatan tarik tertinggi pada 30 menit $(279 \mathrm{MPa})$ dengan modulus tarik $4360 \mathrm{MPa}$. Setelah itu kekuatan tarik komposit epoksi/serat gelas juga menunjukkan tren yang sama dengan komposit epoksi/serat karbon dimana kekuatan tarik cenderung konstan dengan nilai kekuatan tarik $267 \mathrm{MPa}$.

Nilai kekuatan tarik yang tidak mengalami perubahan signifikan setelah curing time 30 hingga 70 menit memberikan petunjuk bahwa pada curing time 30 menit, matriks telah mengalami fase final cure, yaitu keadaan dimana campuran resin dan hardener telah mengalami solidifikasi sempurna sehingga lamanya waktu penekanan dengan temperatur yang sama tidak lagi memberikan pengaruh terhadap kekuatan tarik komposit. Hasil penelitian ini juga didukung oleh (Kwak dkk, 2015), yang memanfaatkan sistem pemanasan eksternal pada pembentukan komposit epoksi/serat karbon dimana nilai kekuatan tarik komposit yang dihasilkan cenderung konstan setelah curing time 30 menit. Berdasarkan hasil yang dilaporkan oleh setyoko, penelitian ini dapat mengoptimalkan waktu pembentukan komposit khususnya pada metode bladder compression moulding hingga 50\% curing time.

Hubungan kekuatan tarik dan variasi curing time ditunjukkan pada Gambar 6. Adapun hubungan modulus tarik dan variasi curing time juga menunjukkan modulus tarik komposit epoksi/serat karbon rata-rata lebih tinggi dibanding komposit epoksi/serat gelas pada semua variasi curing time seperti pada Gambar 7. 


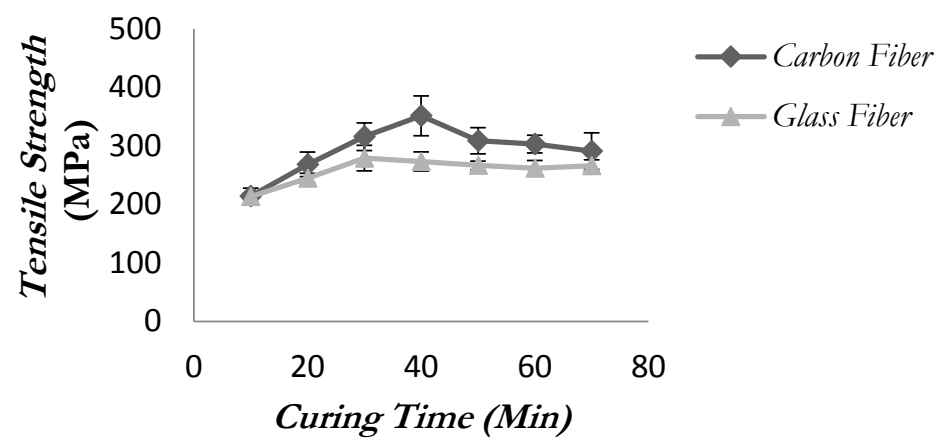

Gambar 6. Hubungan kekuatan tarik (MPa) dan variasi curing time (menit).

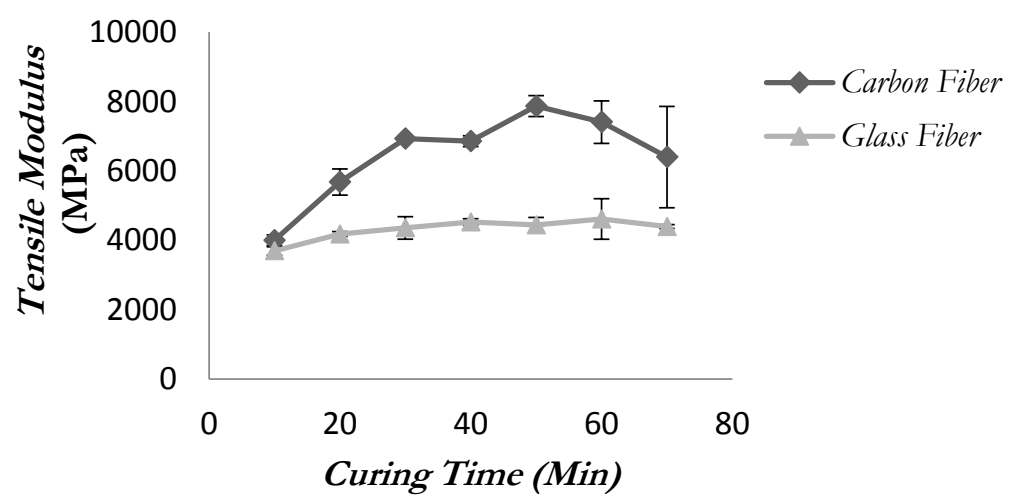

Gambar 7. Hubungan Modulus tarik (MPa) dan variasi curing time (menit)

Selanjutnya, dilakukan pengujian porositas untuk mengetahui pengaruh curing time terhadap porositas serta hubungannya dengan kekuatan tarik komposit. Porositas dapat diakibatkan oleh udara yang terperangkap saat proses hand lay up dan tidak berhasil keluar dari laminasi selama proses pembentukan komposit.

Hasil pengujian porositas menunjukkan bahwa pada komposit epoksi/serat karbon porositas menurun dari curing time 10 menit (2,1\%) menjadi 1,83\% pada curing time 30 menit. Selanjutnya nilai porositas tidak mengalami perubahan yang signifikan hingga curing time 70 menit dengan nilai porositas rata-rata 1,8\%. Adapun pada komposit epoksi/serat gelas, porositas cenderung menurun dari curing time 10 hingga 70 menit. porositas tertinggi komposit epoksi/serat gelas pada curing time 10 menit (1,83\%). Porositas komposit yang dihasilkan pada pembentukan komposit dengan metode bladder compression molding pada tekanan 7 Bar dan temperatur $120^{\circ} \mathrm{C}$ lebih rendah jika dibandingkan dengan metode compression dengan sistem pemanasan eksternal menggunakan oven yaitu 2,97\% - 3,8\% (Diptikanta dkk, 2019). Hasil pengujian porositas menunjukkan hubungan porositas dengan kekuatan tarik komposit yaitu semakin rendah porositas komposit maka kekuatan tarik semakin meningkat.

Grafik hubungan porositas komposit dan variasi curing time pada pembentukan komposit dengan temperatur $120^{\circ} \mathrm{C}$ ditampilkan pada Gambar 8 


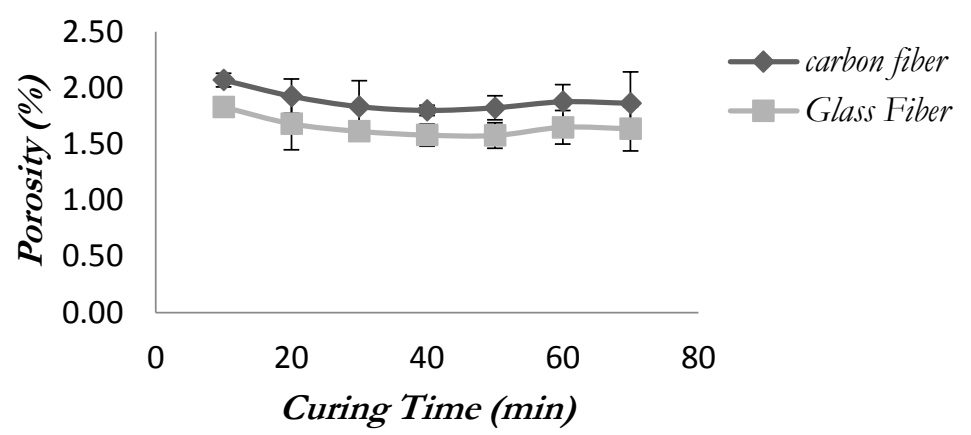

Gambar 8. Hubungan Porositas (\%) dan variasi curing time (menit)

\section{KESIMPULAN}

Beberapa poin yang dapat disimpulkan dari penelitian ini adalah sebagai berikut.

1. Kekuatan tarik tertinggi komposit epoksi/serat karbon diperoleh pada curing time 40 menit (351 MPa) dan pada curing time 30 menit komposit epoksi/serat gelas dengan nilai kekuatan tarik $279 \mathrm{MPa})$.

2. Waktu optimum pada pembentukan komposit epoksi/ serat karbon dan komposit epoksi/serat gelas dengan metode bladder compression moulding pada temperatur $120^{\circ} \mathrm{C}$ dan tekanan 7 Bar yaitu 30 menit.

3. Pemanasan dan penekanan diatas waktu optimum tidak memberikan pengaruh signifikan terhadap kekuatan tarik komposit sehingga tidak menguntungkan dalam suatu proses manufaktur.

\section{DAFTAR PUSTAKA}

Anderson, J. \& Altan, M. C., 2014, Bladder Assisted Composite Manufacturing (BACM): Challenges and Opportunities, Polymer Processing Society Europe-Africa Conference, 134, hal 2-13.

Anderson, J., \& Altan, M. 2012, Properties of Composite Cylinders Fabricated by Bladder Assisted Composite Manufacturing, Journal of Engineering Materials and Technology 134, hal 1-7.

Antonius Dwi Setyoko, 2018, Pengaruh Temperatur Curing Terhadap Sifat Mekanik Pada Manufaktur Komposit Serat Karbon/Epoksi dengan Metoda Pembentukan Bladder Compression Moulding, Tesis, Program Pasca Sarjana Teknik Mesin, Univ. Gadjah Mada, Yogyakarta.

ASM Handbook, 2000, Mechanical Testing and Evaluation, ASM Handbook Vol. 8. Materials Park, 44073-0002.

Budi Purwanto Antameng, 2020, Desain Cetakan yang Efektif dalam Konsumsi Energi untuk Manufaktur Produk Hollow Composite dengan Metode Bladder Compression Molding. Tesis, Program Pasca Sarjana Teknik Mesin, Univ. Gadjah Mada, Yogyakarta.

Diptikanta Das, Sandeep Kumar Pradhan, Ramesh Kumar Nayak, Basanta Kumar Nanda,Bharat Chandra Routara 2019, Influence of Curing Time on Properties of CFRP 
Composites: A Case Study, Materials Today: Proceedings, Volume 26, Part 2, Hal. 344349.

Ignatius Henry Ismadi, 2018, Pengaruh Tekanan Terhadap Sifat Mekanik Pada Manufaktur Komposit Serat Karbon/Epoksi dengan Metoda Bladder Compression Moulding. Tesis, Program Pasca Sarjana Teknik Mesin, Univ. Gadjah Mada, Yogyakarta.

Jones, R. M., 1999, Mechanics of Composite Materials, Taylor \& Francis Group, Philadelphia. Kwak, M., Robinson, P., Bismarck, A., \& Wise, R., 2015, Microwave Curing of Carbon-Epoksi Composites: Penetration Depth and Material Characterisation. Composites: Part A,Volume 75, 18-27.

Mallick, P.K. 2007, Fiber Reinforced Compositesmaterials, Manufacturing and Design, Michigan, CRC Press.

Mazumdar,S.K., 2002, Composite Manufacturing, Materials, Product, and Process Engineering. New York, CRC Press.

S.B. Singh, Sudhir Vummadisetti, Himanshu Chawla. 2018, Influence of Curing on the Mechanical Performance of FRP Laminates, Journal of Building Engineering,vol. 16 119. 